\title{
Peculiarities of gas bubble movement in limited volume of viscous liquid
}

\begin{abstract}
The results of an experimental study of the motion of a gas bubble in a limited volume of a viscous liquid are presented. The influence of the velocity of the fluid on the location of the gas bubble in its volume is shown. A method for calculating the process is proposed and a block diagram for calculating its parameters is developed. In the calculations, the speed of the rotational motion of the viscous fluid, the volume of the gas space, and the physical properties of the liquid are taken into account. The gas space, which is in the static position above the liquid level, when rotating, creates a bubble of a spherical shape that moves along the volume of the liquid to make it move in the vessel. Such mixing can cause intensification of various technological processes.
\end{abstract}

Volume 2 Issue 3 - 2018

Yakov G Verkhivker, Ella I Altman

Odessa National Academy of Food Technologies, Ukraine

Correspondence: Yakov G Verkhivker, Odessa National Academy of Food Technologies, Ukraine,

Email yaverkhivker@gmail.com

Received: March 01, 2018| Published: June 11, 2018

Keywords: bubble, rotation, viscous fluid

\section{Formulation of the problem}

When solving many technical and technological problems, ${ }^{1,2}$ it becomes necessary to select the modes of motion of a gas bubble in a limited volume of a viscous fluid. ${ }^{3,4} \mathrm{~A}$ gas bubble, when rotating a bounded volume of a viscous liquid, changes its geometric position in the volume of a viscous liquid and thus has a different effect on the viscous liquid, changing its parameters, in particular the pressure, or mixing it. Under the action of the rotational force, the gas bubble moves in the volume of the viscous liquid and, thus, mixes it. Without the motion of a closed volume of viscous fluid, the gas bubble occupies a position in the upper part of the closed volume and does not move in any way in the liquid. With an increase in the speed of rotation of the liquid, the gas bubble begins to move in the liquid and occupies various positions in the volume of the liquid, beginning to mix it. Achieving a certain value of the rotation speed of a limited volume of a viscous fluid leads to a maximum velocity of motion of a gas bubble in it. A further increase in the speed of motion leads to the fact that the gas bubble hangs in the volume of the liquid and ceases to move in it, that is, the perforation effect disappears. These provisions, which are confirmed experimentally, are the basis for the developed methodology and a block of the scheme for calculating the optimal velocity of a closed volume of a viscous liquid with the presence of a gas bubble in it. The difference in the densities of gas and liquid leads to the effect of the emergence of a gas bubble in the volume of the liquid and at the same time it ceases to fulfill the necessary technological function. The velocity of the ascent of the gas bubble can be calculated from the known relation. ${ }^{5}$

$$
U=\left(\frac{1,306 \cdot \sigma^{2} \cdot \rho_{1}}{\rho_{2} \cdot \mu}\right)^{0,2}
$$

where:

$\sigma$-The coefficient of the surface tension of the liquid;

$\rho_{1}$ and $\rho_{2}$-The gas and liquid densities, respectively;

$\mu$-The coefficient of fluid kinematic viscosity;

U-The velocity of the ascent (ascent) of the gas bubble.

Since the defining size of a gas bubble is its equivalent diameter, calculated from the relation ${ }^{6}$

$$
D_{e}=\frac{4 F}{P}
$$

where:

$$
\text { F - The area of the outer surface of the gas bubble; }
$$

$\mathrm{P}$ - The perimeter of the gas bubble, then it is possible to determine the conditions of immobility of the gas bubble inside the volume of the liquid during its motion. Since the resistance to the motion of a gas bubble in a liquid $\mathrm{N}$ can be written as ${ }^{5}$

Where:

$$
\mathrm{N}=\frac{\mathrm{A} \rho \mathrm{UD}_{\mathrm{e}}^{2}}{\operatorname{Re}}
$$

A - The coefficient, which depends on the viscosity properties of the liquid;

$\rho$ - The density of the liquid;

Re - The Reynolds similarity number, which is calculated for a liquid.

The aim of the study is to use the above approach to calculate the optimal rotation speed of a closed volume of a viscous fluid. To achieve this goal, it is necessary to develop a block scheme for calculating the above relationships and to conduct a series of studies confirming the data obtained as a result of calculations.

\section{Experimental results}

According to the Figure 1, the following calculations were made:

Block 1 assumes the introduction of the following initial data:

a. The possible range of rotation speed of a limited volume of a viscous liquid;

b. Type and geometric dimensions of a limited volume of a viscous liquid;

c. Degree of filling of a limited volume with a viscous liquid;

d. Type of viscous liquid;

e. Thermo physical and hydrodynamic characteristics of a viscous fluid; 
Block 2 determines the equivalent size of the gas bubble (ratio 2 ) in accordance with the degree of filling the closed volume with a viscous liquid. Block 3 uses the gas bubble defining size, that is, its equivalent diameter, found from the relation (2), to calculate the arrays of linear velocities and the resulting accelerations of the motion of a gas bubble in a given viscous fluid over the entire possible range of the rotational speed of a limited volume of a viscous fluid. Block 4 uses the relation (1) and compares it with the linear velocity of the gas bubble $\mathrm{V}$ in a given fluid. The equality $\mathrm{U}=\mathrm{V}$ occurs at a rotational speed of a closed volume of a viscous fluid at which it affects the motion of a gas bubble. Block 5 uses the original data and relation (2) to calculate the rate of ascent of the gas bubble in this particular case (in a given viscous liquid that is placed in a certain amount in a closed volume of a specific size). Block 6 calculates an array of forces of resistance to the motion of a gas bubble in a closed volume of a viscous fluid at different values of the rotational speed of this volume after the condition $\mathrm{U}=\mathrm{V}$ is reached. Block 7 serves to determine the optimal rotation mode (frequency), from the point of view of achieving the most acceptable indicator (energy consumption, work efficiency, reduction of material costs and etc.).

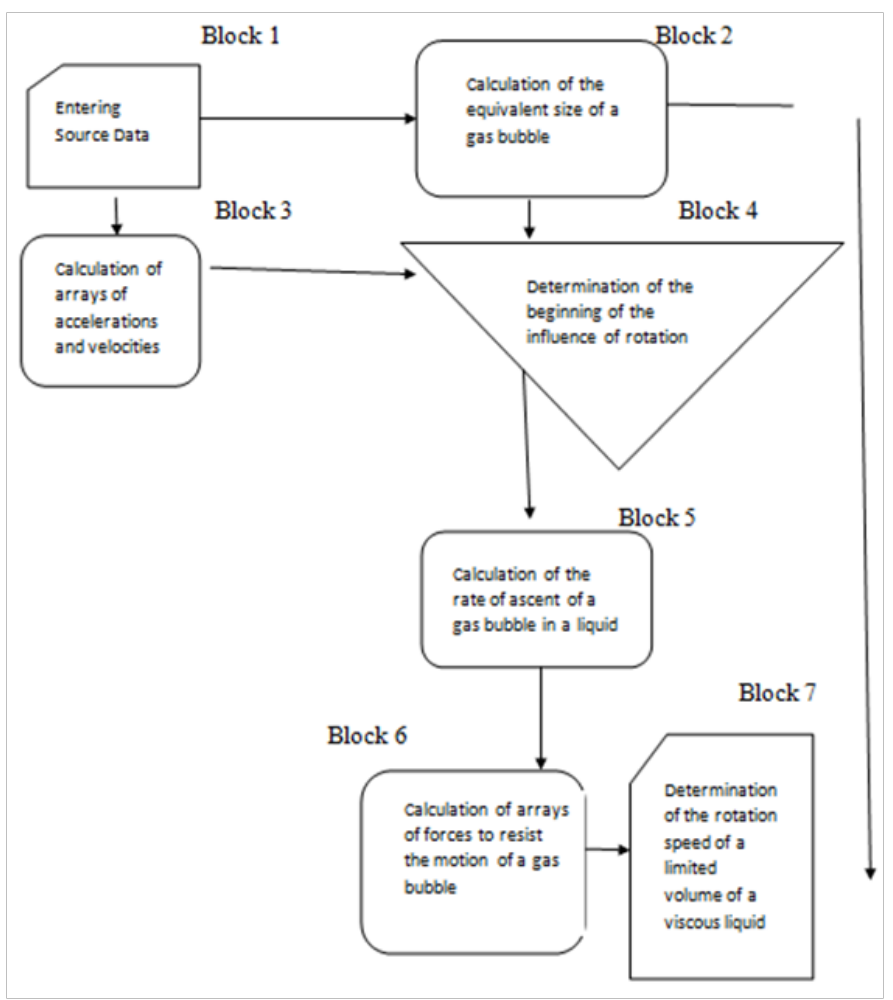

Figure I Block diagram of calculations.

According to the algorithm, a calculation program has been compiled, which has been verified in the process of thermal sterilization of food products. Food products of various viscosities (apple juice with pulp and sugar, tomato sauce) are filled in glass jars with a capacity of $1000 \mathrm{~cm}^{3}$ and $3000 \mathrm{~cm}^{3}$. Jars tightly closed caps. The degree of filling the glass jars with the product was 0.90 . The temperature of the product was from $60^{\circ} \mathrm{C}$ to $95^{\circ} \mathrm{C}$. The rotation frequency varied from $0.20 \mathrm{~s}^{-1}$ to $0.41 \mathrm{~s}^{-1}$.

Table 1 shows the results of experimental studies. Optimization was carried out for energy costs, which are necessary for the process of thermal sterilization of these food products. Compared to a fixed glass jar that is filled with this product, the glass jar rotating with the heat treatment with the product heats up much faster. Thus, energy resources are saved. The intensification of the heating of the product, which is in the glass jar, is due to the motion of the gas bubble. The volume of this gas bubble in this case is 0.1 of the closed volume (the internal capacity of the glass jar, 30 and $10 \mathrm{~cm}^{3}$, respectively). The gas bubble mixes the volume of the product in a glass jar. The optimum speed varies with the temperature of the product (viscous liquid). Table 1 shows the experimental results, which have the good agreement with the calculated values. The differences did not exceed $0.5 \%$.

Table I Experimental results

\begin{tabular}{|c|c|c|c|c|}
\hline $\begin{array}{l}\text { Viscous } \\
\text { liquid }\end{array}$ & $\begin{array}{l}\text { Closed } \\
\text { volume, } \\
\mathrm{cm}^{3}\end{array}$ & $\begin{array}{l}\text { Degree } \\
\text { of filling }\end{array}$ & $\begin{array}{l}\text { Temperature } \\
\text { of viscous } \\
\text { liquid, }{ }^{\circ} \mathrm{C}\end{array}$ & $\begin{array}{l}\text { Optimal } \\
\text { speed, } \\
\mathrm{s}^{-1}\end{array}$ \\
\hline $\begin{array}{l}\text { Apple juice } \\
\text { with pulp } \\
\text { and sugar }\end{array}$ & 3000 & 0,90 & $\begin{array}{l}60 \\
75 \\
95\end{array}$ & $\begin{array}{l}0,36 \\
0,31 \\
0,20\end{array}$ \\
\hline $\begin{array}{l}\text { Tomato } \\
\text { ketchup }\end{array}$ & 1000 & 0,90 & $\begin{array}{l}60 \\
75 \\
95\end{array}$ & $\begin{array}{l}0,41 \\
0,38 \\
0,27\end{array}$ \\
\hline
\end{tabular}

\section{Discussion}

The developed block for calculating the motion of a gas bubble in a limited volume of liquid allowed us to calculate the effective regimes of sterilization and pasteurization of canned food products in various types of consumer containers and in various types of technological equipment. Since the process of heat treatment of canned food products is the most energy-intensive technological process in food production, energy saving in its implementation is a very important factor. Calculations performed on the basis of the presented experiments show that reducing the energy capacity of the process of thermal sterilization with the use of a mixing effect saves up to $22 \%$ of the time for carrying out the technological regime. Since the reduction in the time of heat treatment of food products while maintaining their qualitative microbiological indicators leads not only to an improvement in the energy costs of production, but also to the preservation of the nutritional value of food products..$^{7-9}$

\section{Acknowledgements}

None.

\section{Conflict of interest}

The author declares there is no conflict of interest.

\section{References}

1. Kasatkin AG. Basic processes and apparatuses of chemical technology. Textbook for High Schools. 2009.

2. Sudakov EN. Calculations of the main processes and apparatuses of oil refining. Textbook for High Schools. 1974.

3. Nilmani M, Maxwell TT, Robertson DGC, et al. Prediction of initial motion of a gas bubble in liquids. Appl Math Modelling. 1981;5(1):2428 .

4. Aybers NM, Tapucu A. The motion of gas bubbles rising through stagnant liquid. Wärme - und Stoffübertragung. 1969;2(2):118-128. 
5. Verkin BM, Kirichenko Yu A, Rusakov KV. Heat transfer at boiling in fields of mass forces of various intensity. Kiev Scientific Thought. $1988 ; 254$.

6. Lovelock DW, Olivant DJ. Philosophical aspects of heat processing. Journal of food science. 1980;190-206

7. Pilipenko LN, Verkhivker Ya G, Pilipenko IV. Preservation of food products (microbiology, energy, control). Odessa “WWV”. 2015;232.
8. Pilipenko LN, Verkhivker Ya G, Pilipenko IV. Microbiology, energy, packing and control of the canning production scientific publication. $L A P$ LAMBERT Academic Publishing. 2015;80.

9. Aleliers at Chatlersde Bretagne. Sterilization apparatus. Aleliers at Chatlersde Bretagne. 1974. 